\title{
Assisting cultivation of photosynthetic microorganisms by microbial fuel cells to enhance nutrients recovery from wastewater
}

\section{Alessandra Colombo}

Stefania Marzorati

Giorgio Lucchini

Pierangela Cristiani ${ }^{b}$

Deepak Pan

Andrea Schievano ${ }^{\mathrm{a}, *}$

andrea.schievano@unimi.it

aDepartment of Agricultural and Environmental Science (DiSAA), Università degli Studi di Milano, via Celoria 2, 20133 Milano, Italy

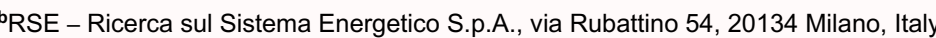

'Separation \& Conversion Technology, Flemish Institute for Technological Research (VITO), Boeretang 200, 2400 Mol, Belgium

${ }^{*}$ Corresponding author

\section{Abstract}

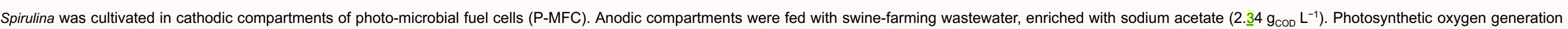

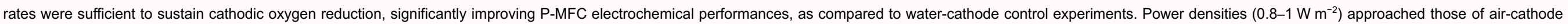

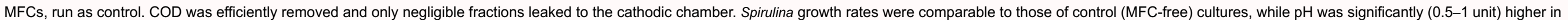

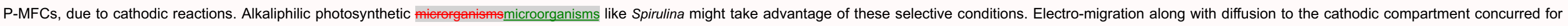
the recovery of most nutrients. Only $\mathrm{P}$ and Mg were retained in the anodic chamber. A deeper look into electro-osmotic mechanisms should be addressed in future studies.

Keywords: Photo-microbial fuel cells; Wastewater; Nutrients recovery; Microalgae; Spirulina

\section{Introduction}

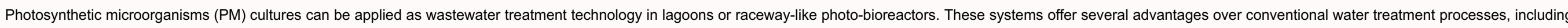

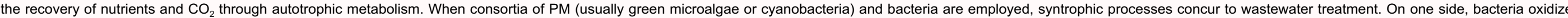

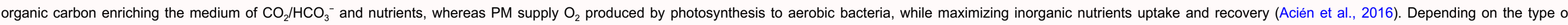

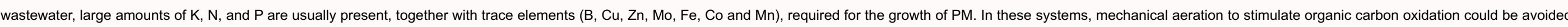

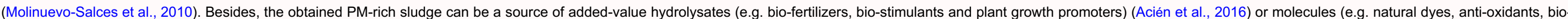
polymers, carotenoids etc.) (Ledda et al., 2016)

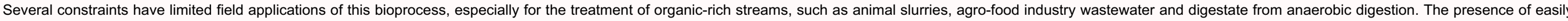

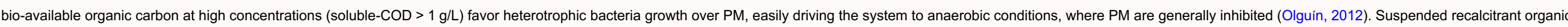

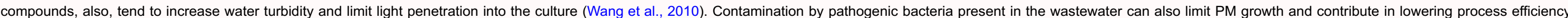




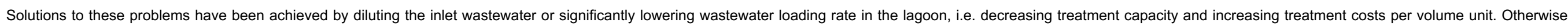

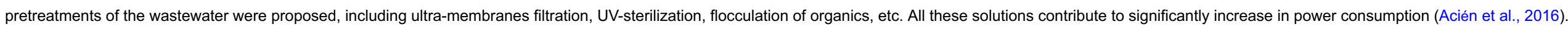

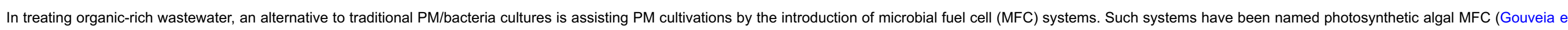

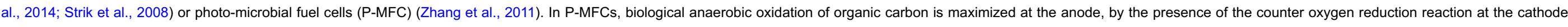

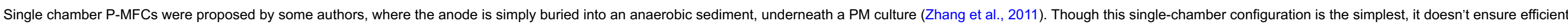
separation between bacteria and PM. This might be a limiting factor, especially for treating wastewater rich in organics and pathogenic-bacteria (e.g. animal manure).

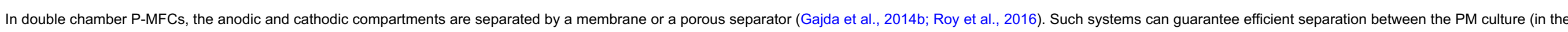

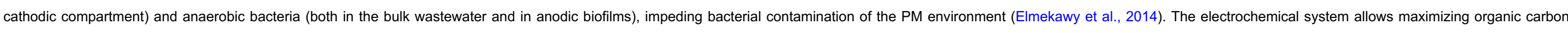

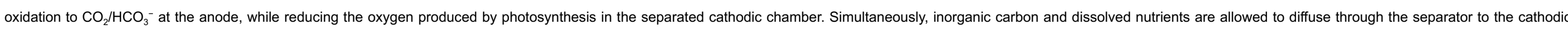
chamber, where PM utilize them as growth medium (see Graphical Abstract).

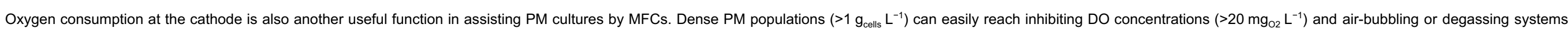
are used to control DO (Carvalho et al., 2006). The cathode works as self-powered oxygen-consuming interface and has the potential to substitute these energy-consuming processes in photo-bioreactors.

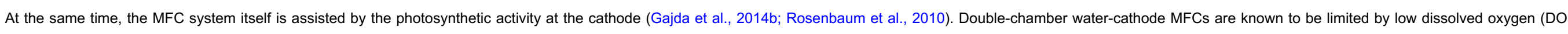

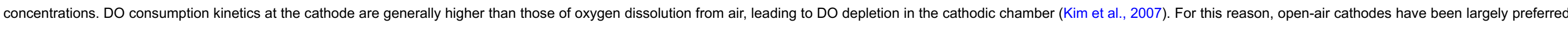

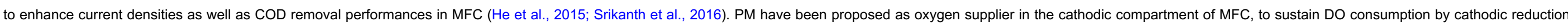
reaction and light intensity has been correlated to DO in a microalgae-assisted cathode (Gajda et al., 2013; González Del Campo et al., 2013; Wu et al., 2014).

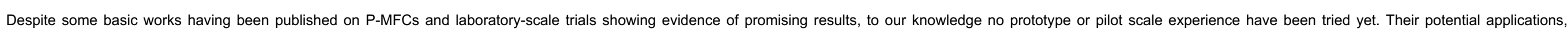

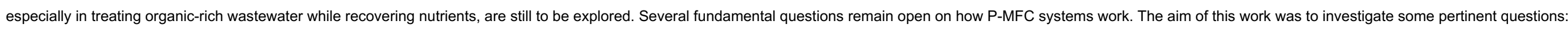

- is photosynthetic oxygen, provided by PM cultivation, sufficient to sustain the performance of the MFC, as compared to air-cathode configurations?

- is PM's growth negatively or positively affected by the presence of the cathode, as compared to a non-assisted PM culture?

- can high concentrations of $\operatorname{COD~(>1~g/L)~be~efficiently~removed~in~the~anodic~compartment,~without~diffusing~to~the~cathodic~chamber?~}$

- how do important parameters (e.g. DO concentrations, pH, conductivity) vary in the PM culture, thanks to the presence of the cathode? how does DO and pH profiles look like at cathode interface?

- can nutrients be removed from the wastewater? What mechanisms can drive nutrients recovery?

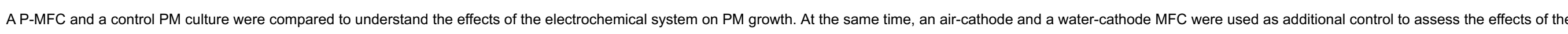
PM culture on the electrochemical system. The water-cathode MFC was also considered as control to measure nutrients diffusion from the anolyte to the cathodic chamber, without the influence of the PM culture.

\section{Materials and methods}

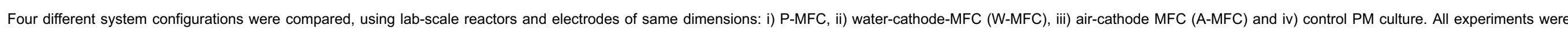
carried out in duplicates (8 reactors overall). Details on reactors and electrode preparation are reported in the following.

\subsection{MFCs configuration}

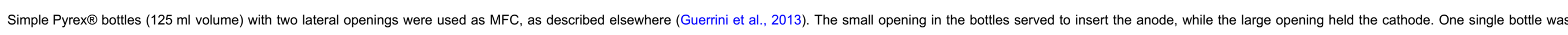

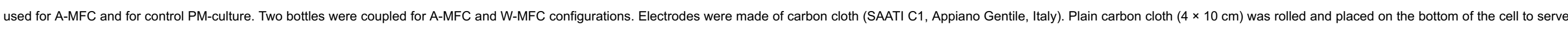




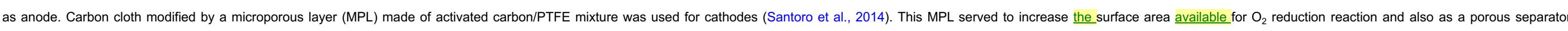

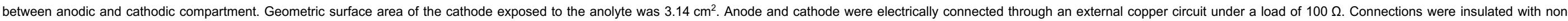
conductive epoxy resin.

\subsection{Start-up phase}

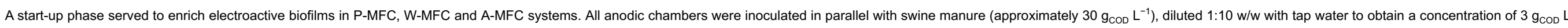
${ }^{-1}$. The chemical composition of the swine-farming wastewater at the beginning of the experiment is reported in Table 1.

Table 1 Chemical composition of the swine-farming wastewater at the beginning of the experiment.

\begin{tabular}{|c|c|c|}
\hline Element & Total content $(\mu \mathrm{g} / \mathrm{L})$ & Dissolved fractiona $(\mu \mathrm{g} / \mathrm{L})$ \\
\hline $\mathrm{Na}$ & 86701 & 70421 \\
\hline Mg & 31633 & 17031 \\
\hline K & 274673 & 221501 \\
\hline $\mathrm{Ca}$ & 17989 & 12721 \\
\hline $\mathrm{Cr}$ & 7 & 4 \\
\hline $\mathrm{Mn}$ & 561 & 190 \\
\hline $\mathrm{Fe}$ & 10067 & 971 \\
\hline Co & 9 & 7 \\
\hline $\mathrm{Ni}$ & 51 & 37 \\
\hline $\mathrm{Cu}$ & 1457 & 118 \\
\hline $\mathrm{Zn}$ & 10099 & 974 \\
\hline$P$ & 58906 & 36692 \\
\hline $\mathrm{N}-\mathrm{NH}_{4}^{+}$ & - & 217000 \\
\hline
\end{tabular}

${ }^{\mathrm{a}}$ Measured after microfiltration $(0.2 \mu \mathrm{m})$.

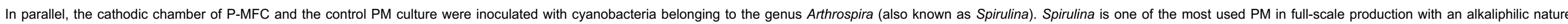

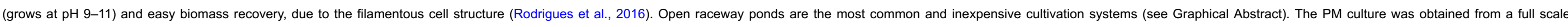

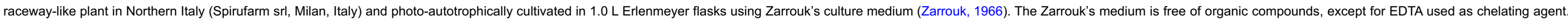

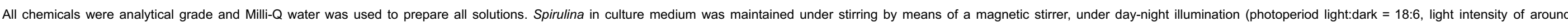
$\left.60-80 \mu \mathrm{E} \mathrm{m}^{-2} \mathrm{~s}^{-1}\right)$ by a white fluorescent lamp $(6400 \mathrm{~K})$ and at constant temperature $\left(25 \pm 1^{\circ} \mathrm{C}\right)$ (Chen and Zhang, 1997).

\subsection{Experiment}

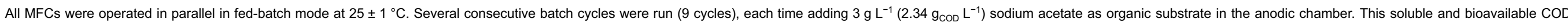

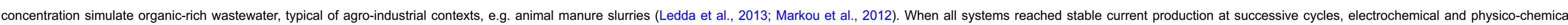
parameters were measured.

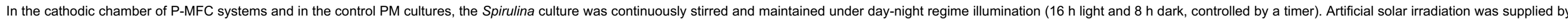




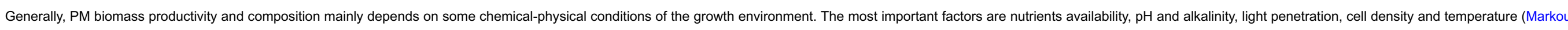

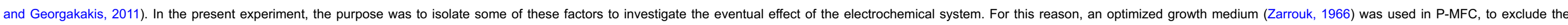
variable of eventual lack of nutrients.

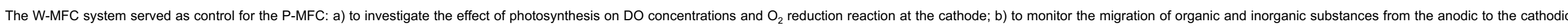
chamber. The cathodic chamber was initially filled with water, to allow nutrients detection by ICP-MS. Three times during the experimental period, water was completely replaced with fresh water and analyzed.

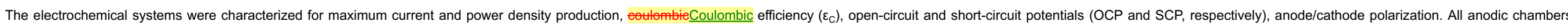

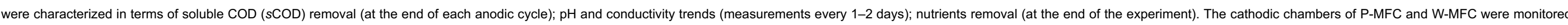

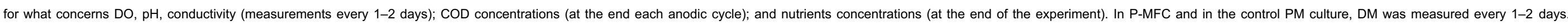
Microelectrodes were used to measure $\mathrm{DO}$ and pH at the interface of the porous separation layer, on both anodic and cathodic side. All details for analytical procedures are reported in Section 2.4.

\subsection{Chemical analyses}

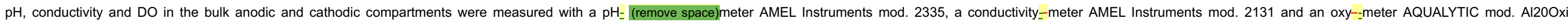

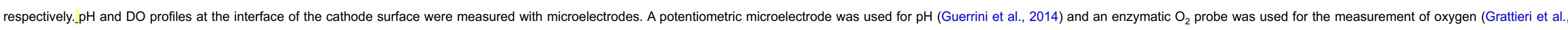

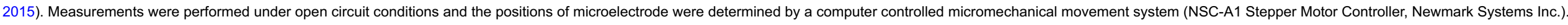

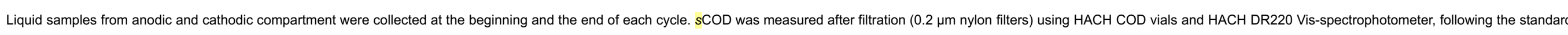

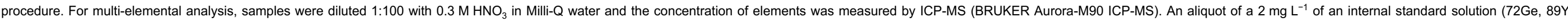

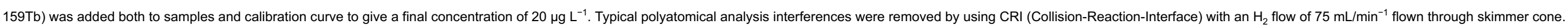

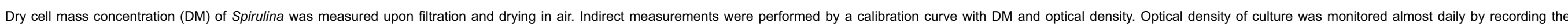
absorbance spectra with a HACH DR2000 Vis-spectrophotometer.

\subsection{Electrochemical analysis}

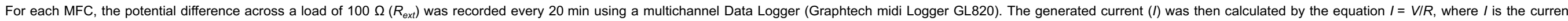

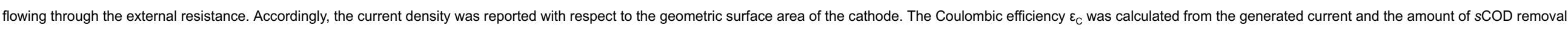

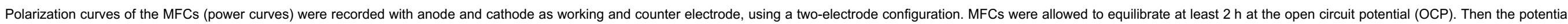
was linearly varied from the OCP to $10 \mathrm{mV}$ at a scan rate of $10 \mathrm{mV} / \mathrm{min}$. Internal resistance $\left(R_{\text {int }}\right)$ of MFCs was then calculated by the equation $P_{\max }=R_{\text {int }} / I_{\text {max }}{ }^{2}$.

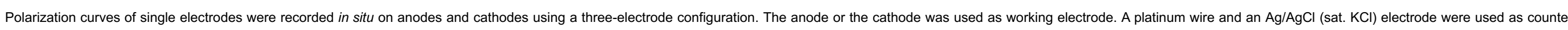

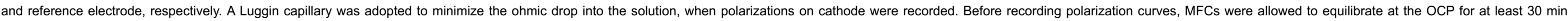
Potential was then varied at $10 \mathrm{mV} / \mathrm{min}$ from the OCP in the anodic or cathodic direction.

An EG\&G mod. 273A potentiostat/galvanostat was used to record polarization curves. All the potentials throughout the text are referred to the $\mathrm{Ag} / \mathrm{AgCl}(\mathrm{sat} . \mathrm{KCl})$ electrode.

\section{Results and discussion}

\subsection{Current generation, COD removal and electrochemical properties}

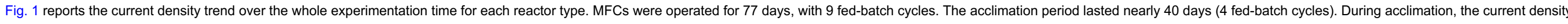

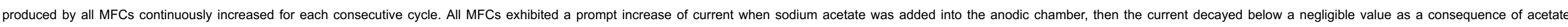



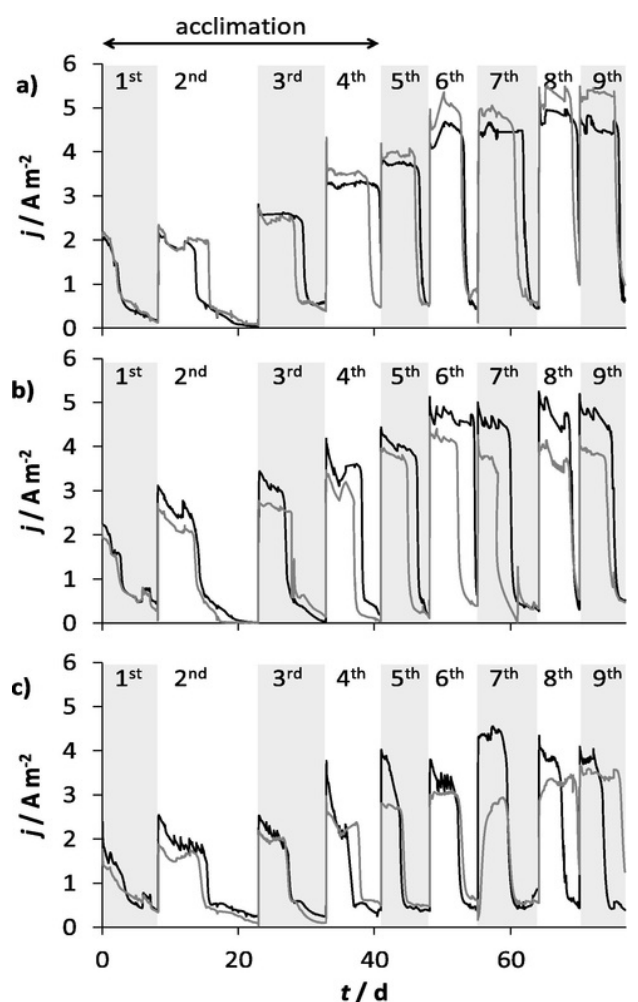

Fig. 1 Comparison of the current density over the whole experimentation period for two MFCs of each type: A-MFC (a): P-MFC (b); W-MFC (c). The duration of the acclimation period and of successive feeding cycles with sodium acetate (3 g/L) are indicated.

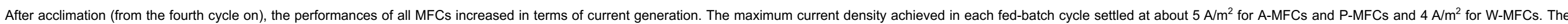

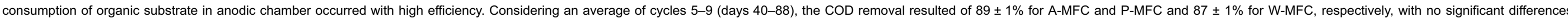

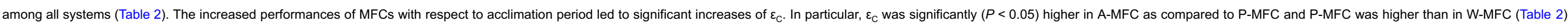
No remarkable differences were found in the ranges of $\mathrm{pH}$ and conductivity, measured in the anodic chambers of all systems (Table 2).

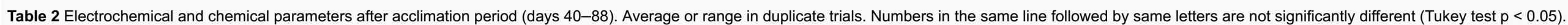

\begin{tabular}{|c|c|c|c|c|c|}
\hline & & P-MFC & A-MFC & W-MFC & PM culture \\
\hline$P_{\max } / \mathrm{W} \mathrm{m^{-2 }}$ & & $0.85 \pm 0.29^{\mathrm{a}}$ & $0.98 \pm 0.13^{\mathrm{a}}$ & $0.51 \pm 0.11^{\mathrm{b}}$ & - \\
\hline$R_{\text {int_- }} / \Omega$ & & 287 & 210 & 429 & - \\
\hline Cell SCP/_mV & & $-442 \pm 60^{a}$ & $-289 \pm 26^{b}$ & $-444 \pm 59^{a}$ & - \\
\hline \multirow[t]{2}{*}{$\mathrm{OCP} / \mathrm{mV}$} & Anodeic & $-524 \pm 30^{a}$ & $-531 \pm 49^{a}$ & $-542 \pm 25^{a}$ & - \\
\hline & Cathodeieie & $26 \pm 44^{a}$ & $25 \pm 44^{a}$ & $27 \pm 44^{a}$ & - \\
\hline Coulombic Efficiency $\left(\varepsilon_{c}\right)$ & & $17.0 \pm 3.3^{\mathrm{ab}}$ & $20.4 \pm 3.9^{\mathrm{a}}$ & $13.4 \pm 3.1^{\mathrm{b}}$ & - \\
\hline
\end{tabular}




\begin{tabular}{|c|c|c|c|c|c|}
\hline$\underline{s} \mathrm{COD}$ removal from anodic chamber_/_\% & & $89 \pm 1^{\text {a }}$ & $89 \pm 1^{\mathrm{a}}$ & $87 \pm 1^{\mathrm{a}}$ & - \\
\hline$\underline{s} \mathrm{COD}$ concentration in cathodic chamber_/_mg $\mathrm{COD} \mathrm{L}^{-1}$ & & $359 \pm 113^{a}$ & - & $48 \pm 34^{b}$ & $221 \pm 84^{\mathrm{a}}$ \\
\hline $\mathrm{DO}$ concentration range in cathodic chamber/_. $\mathrm{mg}_{\mathrm{O} 2} \mathrm{~L}^{-1}$ & & $10-32$ & - & $2-6$ & $12-30$ \\
\hline \multirow[t]{2}{*}{ Bulk pH range } & Anodic & $7.4-8.9$ & $8.1-8.7$ & $7.6-8.8$ & - \\
\hline & Cathodic & $9.7-11.8$ & - & $8.6-12.5$ & $8.9-10.6$ \\
\hline \multirow[t]{2}{*}{ Bulk Conductivity range/_ $\mathrm{mS} \mathrm{cm}^{-1}$} & Anodic & $6.8-8.2$ & $8.0-9.6$ & $5.2-9.3$ & - \\
\hline & Cathodic & $10.4-20.0$ & - & $0.4-3.9$ & $16-18$ \\
\hline
\end{tabular}

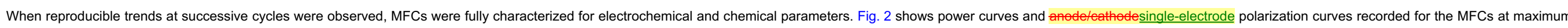

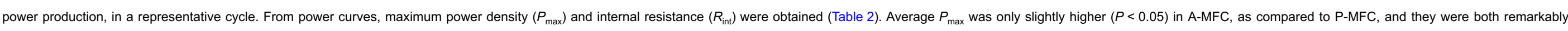
higher than W-MFC. Vice versa, $R_{\text {int }}$ was very different for the three systems, the lowest for A-MFC. Average SCP was $(P<0.05)$ less negative in A-MFC as compared to both P-MFC and W-MFC (Table 2).
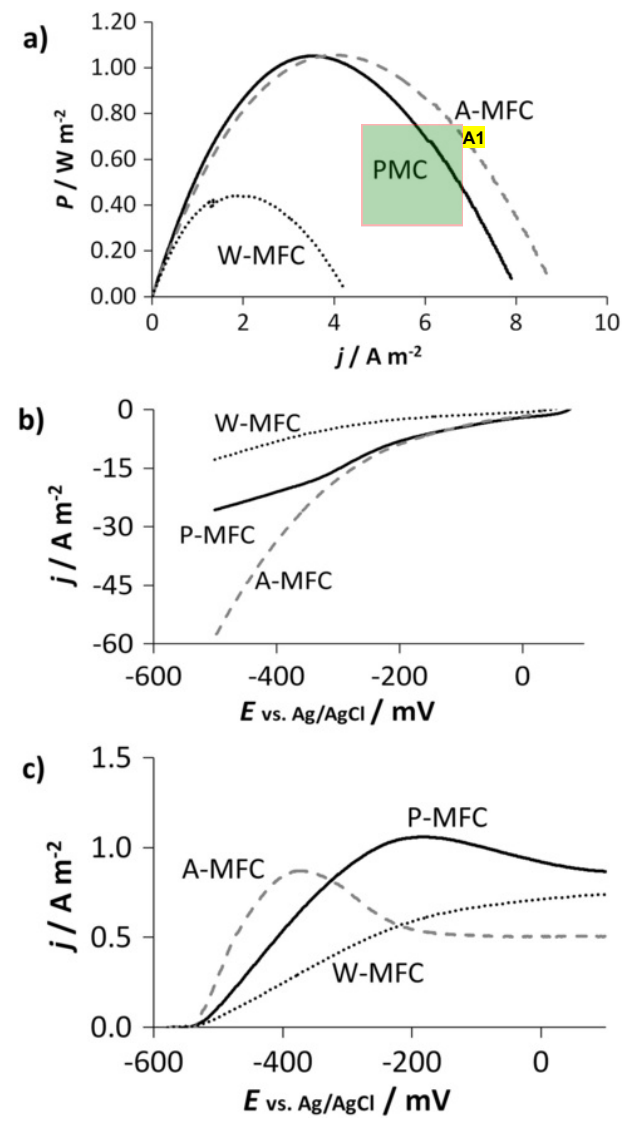

Fig. 2 Electrochemical characterization of MFC systems at day 72: Power curves of MFCs (a); polarization curves recorded on cathodes (b) and anodes (c). 


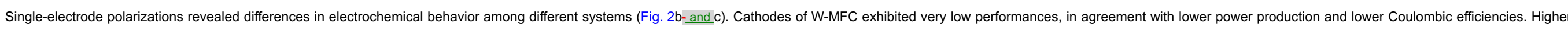

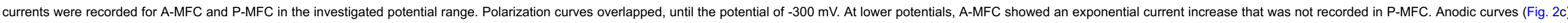

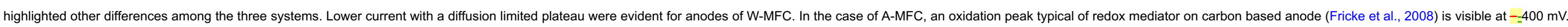

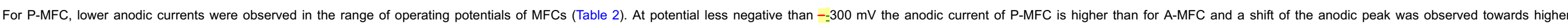
potentials.

\subsection{P-MFC vs A-MFC performances}

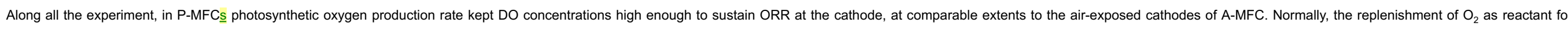

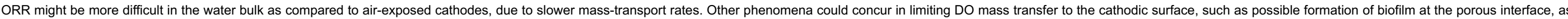

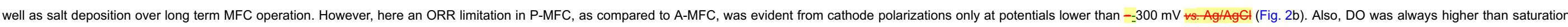

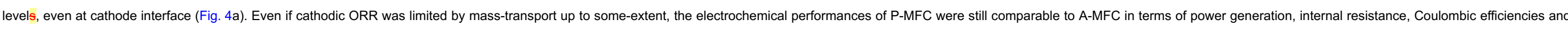
sCOD removal (Table 2). This means that the P-MFC configuration can be used without significant lack of performance of the MFC system, as compared to air-breathing cathode configuration.

a)

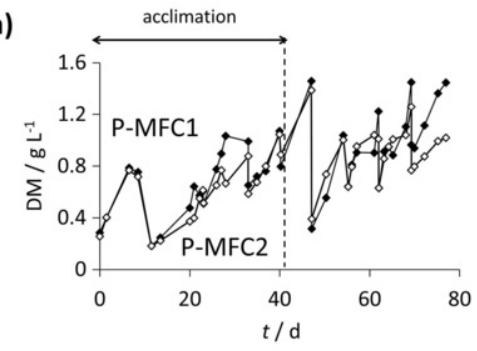

c)

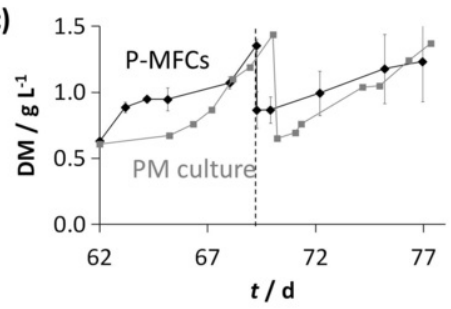

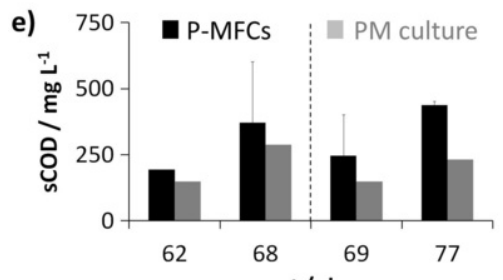

$t / d$

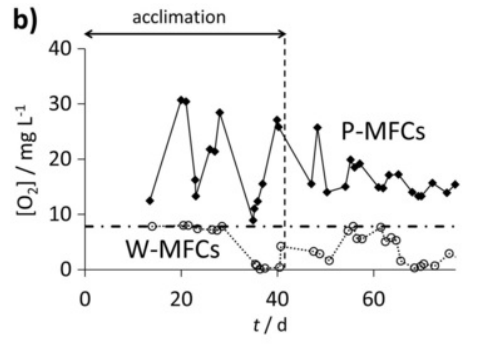

d) 25

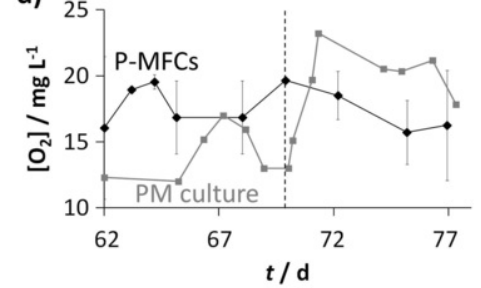

f) 12

동

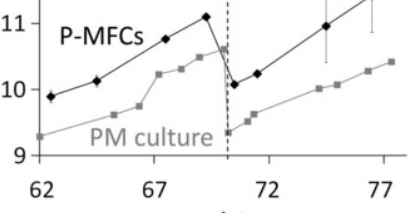

$t / d$

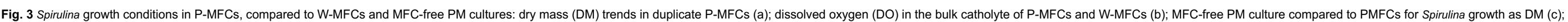

dissolved oxygen DO (d); soluble-COD (e); pH (f). Dash-dotted line refers to waster saturation DO concentration at experimental conditions. 

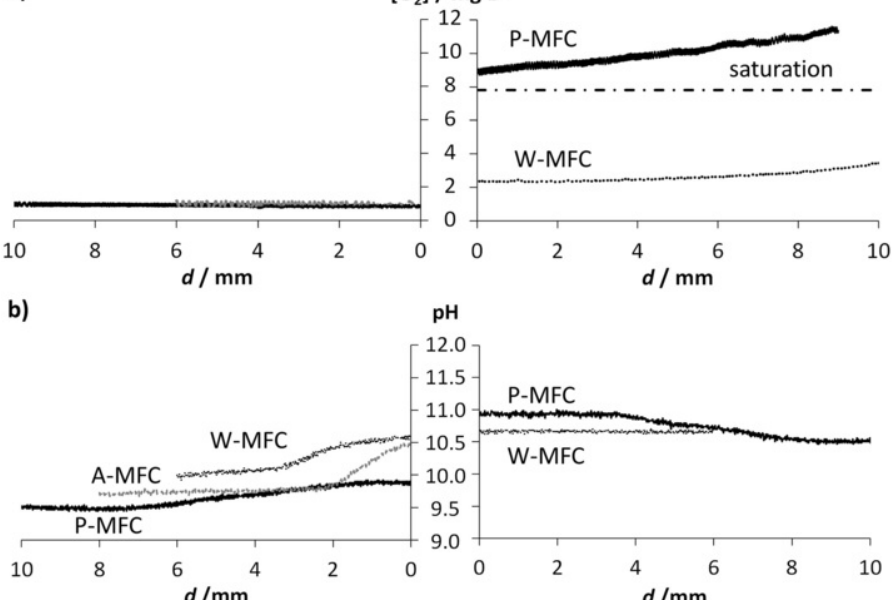

Fig. 4 Dissolved oxygen DO (a) and pH (b) profiles approaching the cathode of MFCs from both the anodic and cathodic compartment (dashed-dotted line refers to DO oxygen at saturation in water). The $x$-axis reports the distance from the cathode surface.

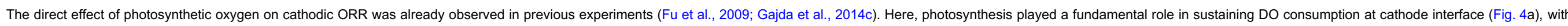
significantly improved performances of P-MFC, as compared to W-MFC (Fig. 2). In absence of PM (W-MFC), both bulk-phase and interface DO concentrations remained always far below saturation (Figs. 3b and 4a).

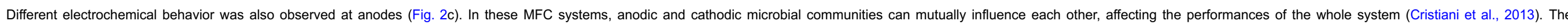

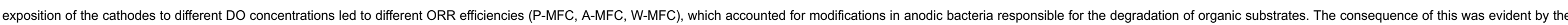
significant increase in Coulombic efficiency for increasing cathodic and anodic performances in P-MFC as compared to W-MFC (Table 2).

\subsection{Conditions and growth of the PM cultures}

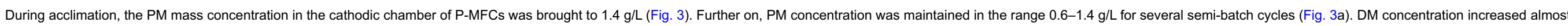
linearly at each cycle. Moreover, no significant differences in PM growth were detected in duplicates P-MFCs.

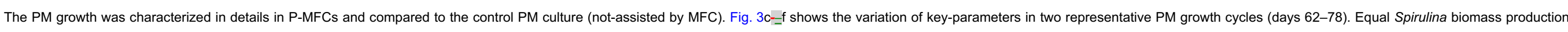

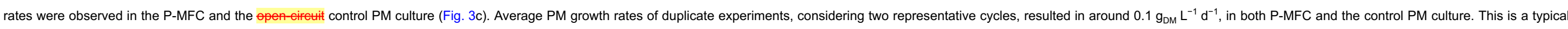
growth rate for Spirulina cultivation under similar conditions of day/night illumination (Chen and Zhang, 1997).

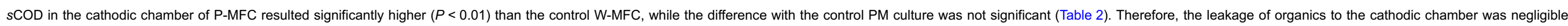

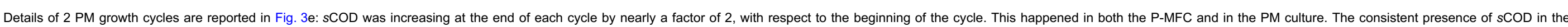
cathodic compartment of P-MFC has to be ascribed mainly to the PM culture itself: PM are known to produce extracellular substances (Filali Mouhim et al., 1993).

\subsection{DO and pH trends in the bulk and at anode-cathode interface}

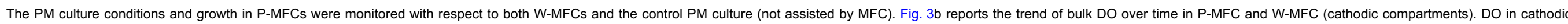

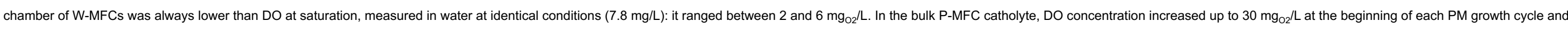
always remained higher than saturation (around $18 \mathrm{mg}_{\mathrm{O} 2} / \mathrm{L}$ as average). Comparable DO trends along significant cycles were measured in both P-MFCs and control culture, in the range $12-25 \mathrm{mg} / \mathrm{O} / \mathrm{L}$ (Fig. $3 \mathrm{~d}$ ).

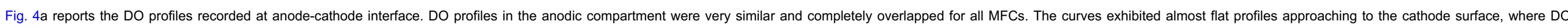




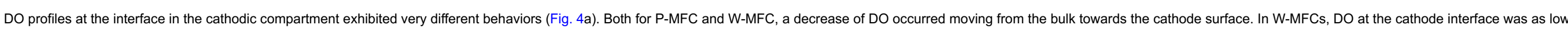

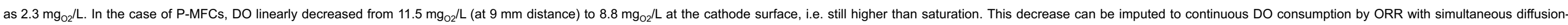
limited mass transport from the bulk.

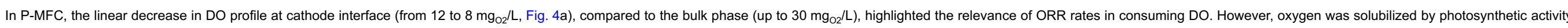

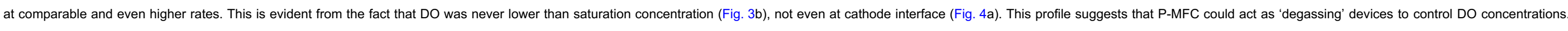

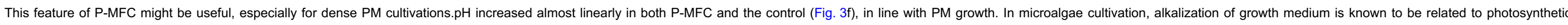

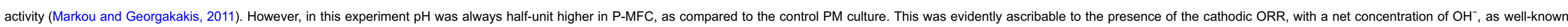
phenomenon in MFCs (Guerrini et al., 2013; Winfield et al., 2016).

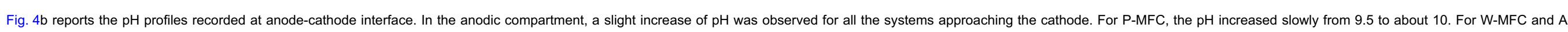

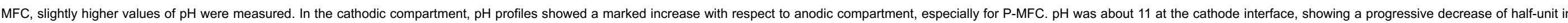

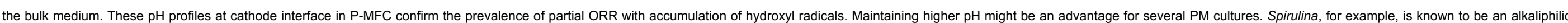

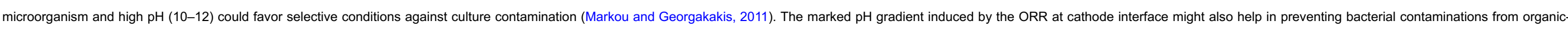

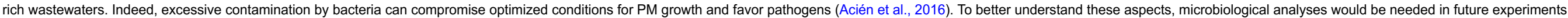

\subsection{Nutrients recovery from wastewater}

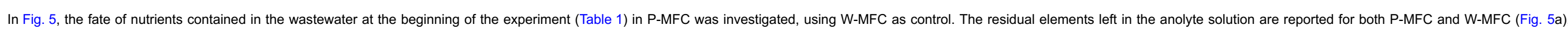

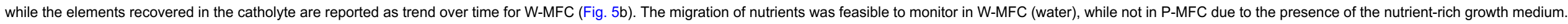
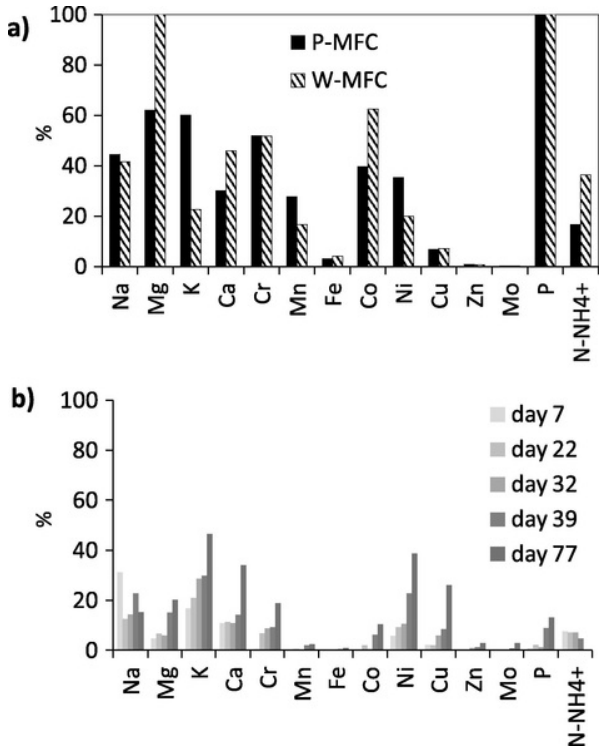

Fig. 5 a) Residual elements in anodic chamber at day 65, in both P-MFCs and W-MFCs. b) Trend of element recovery in the cathodic chamber of W-MFC, during the experiment. All data are reported as percentage of the total content in the wastewater at day 0.

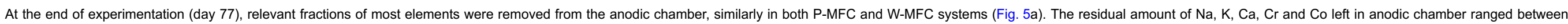




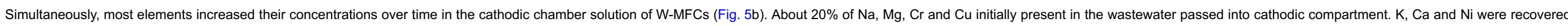

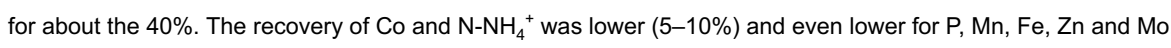

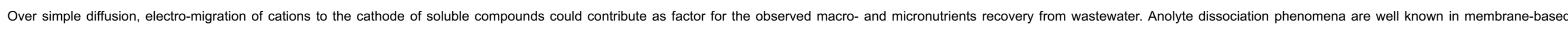
electrochemical systems and in MFCs (Gajda et al., 2014a). Like in electrodialysis studies, the electrical field applied over the separator induces ions migration to the oppositely-charged electrode (Zhu and Logan, 2014).

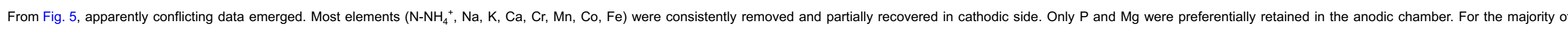

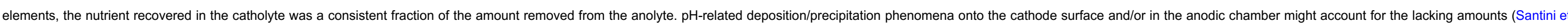
al., 2015).

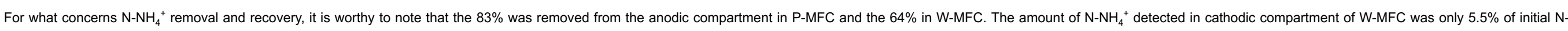

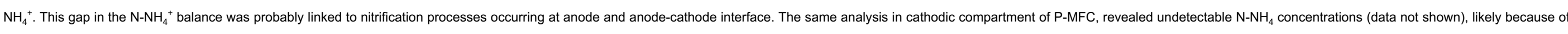

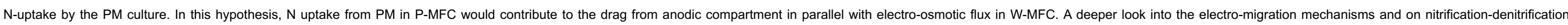
processes should be addressed in future studies, to strike a more precise $\mathrm{N}$ balance.

\section{Conclusions}

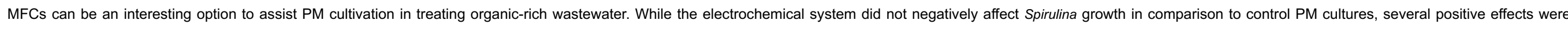

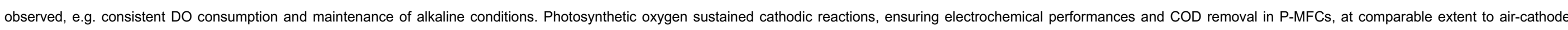

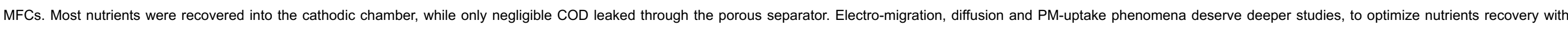
MFC-assisted PM cultivations.

\section{Acknowledgements}

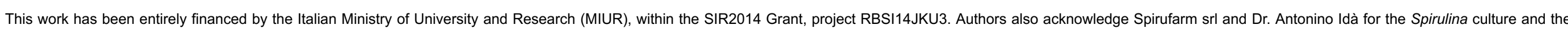
pictures in the artwork. A thank goes to Dr. Claudio Ledda for his precious suggestions

\section{References}

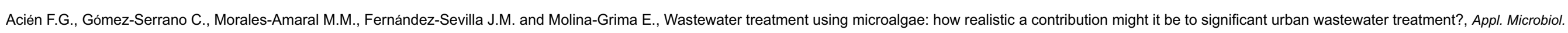

Biotechnol. 100, 2016, 9013-9022, http://dx.doi.org/10.1007/s00253-016-7835-7.

Cai T., Park S.Y. and Li Y., Nutrient recovery from wastewater streams by microalgae: status and prospects, Renew. Sustain. Energy Rev. 19, 2013, 360-369, http://dx.doi.org/10.1016/j.rser.2012.11.030.

Carvalho A.P., Meireles L.A. and Malcata F.X., Microalgal reactors: a review of enclosed system designs and performances, Biotechnol. Prog. 22, 2006, 1490-1506, http://dx.doi.org/10.1021/bp060065r.

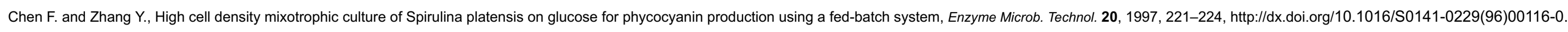

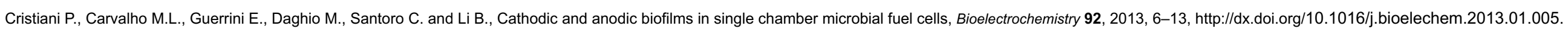

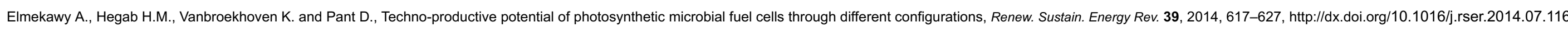

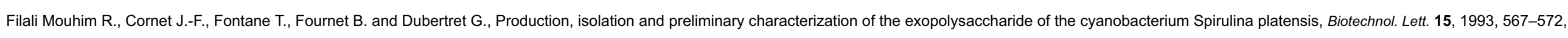

http://dx.doi.org/10.1007/BF00138541.

Fricke K., Harnisch F. and Schröder U., On the use of cyclic voltammetry for the study of anodic electron transfer in microbial fuel cells, Energy Environ. Sci. 1, 2008, 144, http://dx.doi.org/10.1039/b802363h. 


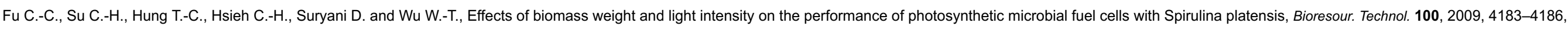
http://dx.doi.org/10.1016/j.biortech.2009.03.059.

Gajda I., Greenman J., Melhuish C. and leropoulos I., Photosynthetic cathodes for microbial fuel cells, Int. J. Hydrogen Energy 38, 2013, 11559-11564, http://dx.doi.org/10.1016/j.ijhydene.2013.02.111.

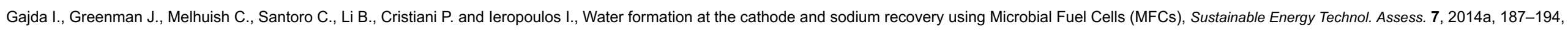
http://dx.doi.org/10.1016/j.seta.2014.05.001.

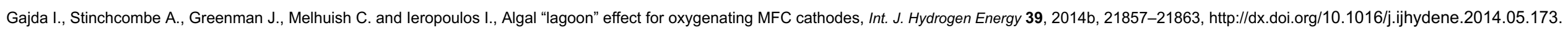

Gajda I., Stinchcombe A., Greenman J., Melhuish C. and leropoulos I., Algal “lagoon” effect for oxygenating MFC cathodes, Int. J. Hydrogen Energy 1-7, 2014c, http://dx.doi.org/10.1016/j.ijhydene.2014.05.173.

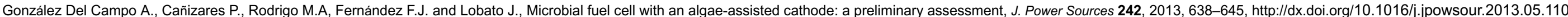

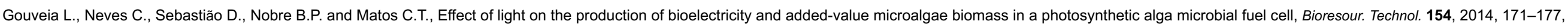
http://dx.doi.org/10.1016/j.biortech.2013.12.049.

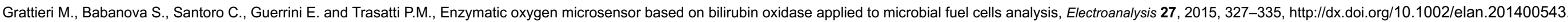

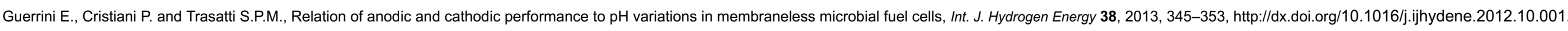

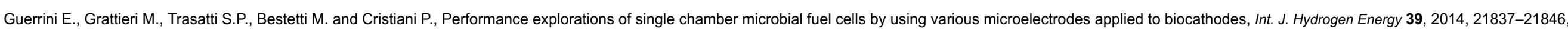
http://dx.doi.org/10.1016/j.ijhydene.2014.06.132.

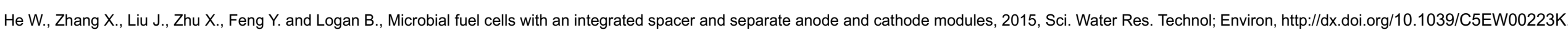

Kim B.H., Chang I.S. and Gadd G.M., Challenges in microbial fuel cell development and operation, Appl. Microbiol. Biotechnol. 76, 2007, 485-494, http://dx.doi.org/10.1007/s00253-007-1027-4.

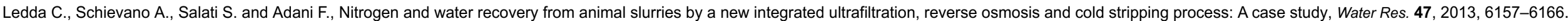

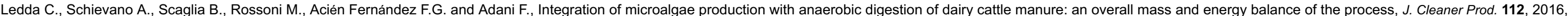
103-112, http://dx.doi.org/10.1016/j.jclepro.2015.07.151.

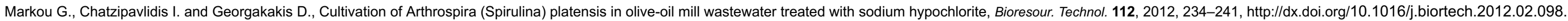

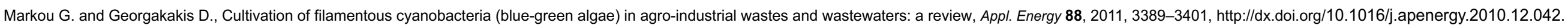

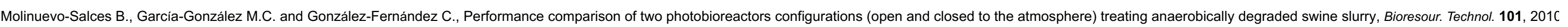
5144-5149, http://dx.doi.org/10.1016/j.biortech.2010.02.006.

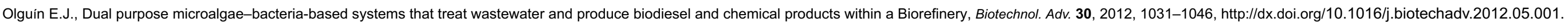

Rodrigues M.S., Ferreira-Camargo L.S., Converti A., Sato S. and Carvalho J.C.M., Ammonium feeding and pH influencing arthrospira platensis growth, composition, and C- and N-uptake, Chem. Eng. Technol. 1-8, 2016, http://dx.doi.org/10.1002/ceat.201500518.

Rosenbaum M., He Z. and Angenent L.T., Light energy to bioelectricity: photosynthetic microbial fuel cells, Curr. Opin. Biotechnol. 21, 2010, 259-264, http://dx.doi.org/10.1016/j.copbio.2010.03.010.

Roy S., Marzorati S., Schievano A. and Pant D., Microbial Fuel Cells, Reference Module in Earth Systems and Environmental Sciences, 2016, Elsevier Inc., 10122-10128, http://dx.doi.org/10.1016/B978-0-12-409548-9.

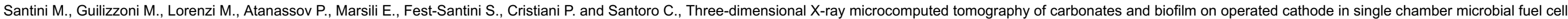
Biointerphases 10, 2015, 31009, http://dx.doi.org/10.1116/1.4930239. 


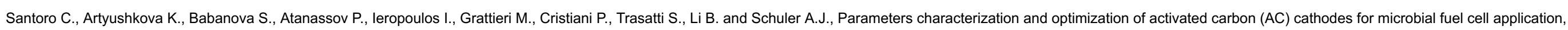
Bioresour. Technol. 163, 2014, 54-63, http://dx.doi.org/10.1016/j.biortech.2014.03.091.

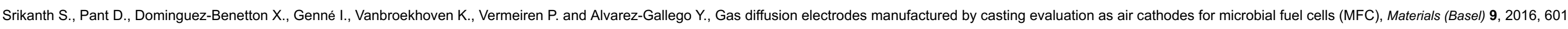
http://dx.doi.org/10.3390/ma9070601.

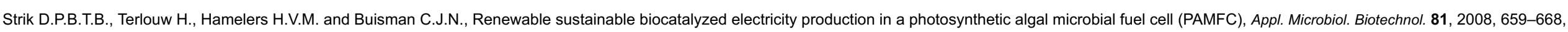
http://dx.doi.org/10.1007/s00253-008-1679-8.

Wang L., Li Y., Chen P., Min M., Chen Y., Zhu J. and Ruan R.R., Anaerobic digested dairy manure as a nutrient supplement for cultivation of oil-rich green microalgae Chlorella sp, Bioresour. Technol. 101, 2010, 2623-2628, http://dx.doi.org/10.1016/j.biortech.2009.10.062.

Winfield J., Gajda I., Greenman J. and leropoulos I., A review into the use of ceramics in microbial fuel cells, Bioresour. Technol. 215, 2016, 296-303, http://dx.doi.org/10.1016/j.biortech.2016.03.135.

Wu Y.C., Wang Z.J., Zheng Y., Xiao Y., Yang Z.H. and Zhao F., Light intensity affects the performance of photo microbial fuel cells with Desmodesmus sp. A8 as cathodic microorganism, Appl. Energy 116, 2014, 86-90, http://dx.doi.org/10.1016/j.apenergy.2013.11.066.

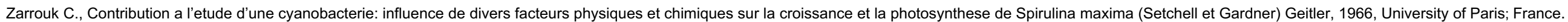

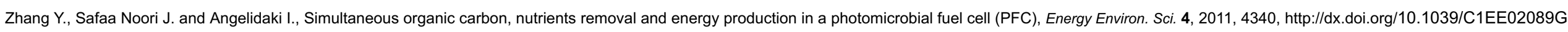
Zhu X. and Logan B.E., Microbial electrolysis desalination and chemical-production cell for $\mathrm{CO}_{2}$ sequestration, Bioresour. Technol. 159, 2014, 24-29, http://dx.doi.org/10.1016/j.biortech.2014.02.062.

\section{Graphical abstract}

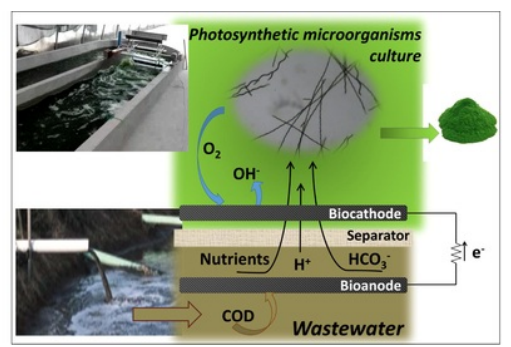

Highlights

- MFC can assist photosynthetic microorganisms cultivation for wastewater treatment.

- Photosynthetic dissolved oxygen sustained cathodic reaction at comparable extent to air-cathode MFCs.

- Efficient removal from anodic chamber prevented COD leakage to the cathodic chamber.

- Cathode helped in consuming photosynthetic oxygen and increased pH in the bulk.

- Nutrients were recovered by electro-migration and diffusion to the cathodic chamber 


\section{Queries and Answers}

Query: Please specify the significance of footnote "a, b, ab" cited in the Table 2, as a corresponding footnote text has not been provided.

Answer: "a, b, ab" are not footnote, but results of statistical Tuket test. Their significance is explained in the caption of the Table 2.

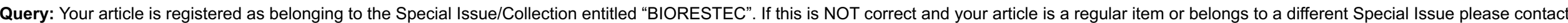
sankara.padmanabhan@elsevier.com immediately prior to returning your corrections.

Answer: The present article belongs to BIORESTEC Special Issue

Query: The author names have been tagged as given names and surnames (surnames are highlighted in teal color). Please confirm if they have been identified correctly.

Answer: Author given names and last names correctly identified. 